\title{
Correlation Study Between Minerals Composition and Porosity Evolution of Black Shale Under Different Oxidation Mechanisms
}

Baolong Zhu ( $\square$ zhubaolong@swust.edu.cn)

Southwest University of Science and Technology https://orcid.org/0000-0003-0517-1100 Jing Li

Southwest University of Science and Technology

Qi Li

Southwest University of Science and Technology

Research article

Keywords: black shale,oxidation,porosity,TOC,Acidithiobacillus ferrooxidans

Posted Date: June 22nd, 2020

DOI: https://doi.org/10.21203/rs.3.rs-36916/v1

License: (c) (i) This work is licensed under a Creative Commons Attribution 4.0 International License.

Read Full License 


\section{Abstract}

The correlation between rock minerals composition and porosity evolution is essential to black shale oxidation,chemical and biological effects may act different roles which is unclear. In present study, the acid solution and Acidithiobacillus ferrooxidans was applied to simulate the chemical and biological effects, the total organic carbon (TOC), pyrite and clay minerals content, porosity characteristics, microsurfacemorphologyof black shale sampleswere employed to analyze the minerals-porosity correlation. Results showed that the chemical effect led to a greaterdecrease of pyrite and increase of clay minerals content than biological effect, which accompanied by a higherspecific surface areas and pore volume. These difference may attribute to the TOCcontent, which decreasedby acid erosion and led to the increase of macropores in chemical group, then promoted the minerals reactions; whereas the TOC content increased byattached and dead bacteria cell bodies on rock surface, led to the increase of micropores and less minerals reactions in biological group. It suggests that the correlation between minerals composition and porosity evolution is different in chemical and biological effects, is mainly due to the different alter trends of TOC content.

\section{Introduction}

Black shale oxidation is a common phenomenon in the Earth's surface supergene environment and is of geological and geoengineering importance [1-8]. A multiple minerals reactions such as pyrite oxidation, clay minerals transformation and organic matters oxidation take place during black shale oxidation, lead to significant changes in shale porosity characteristics $[4,5,9-11]$. These minerals and porosity alterations control the black shale oxidation kinetic rates through impacting the fluids-minerals reactions areas $[1,3,4,12,13]$.

Correlations between the minerals composition and porosity evolution of black shale have been well established, the decrease of pyrite and increase of clay minerals were proven to increase the shale porosity $[4,5,14,15]$, but the role of organic matters remained open to debate. For example, Fisher et al, proposed the organic matters increased the specific surface area of black shale samples [11], Yang et al, made a similar conclusion based on laboratory studies [16]. But based on field investigations, researchers reported a negative correlation between organic matter content and rock porosity on weathered profiles [4, 5]. Interestingly, in spite the total organic carbon (TOC) content decrease on regolith profiles, Jin et al, also reported an addition of modern organic matters on the profiles surface and attributed this phenomenon to the biota turbulence [4]. Therefore, the contradict roles of organic matters in shale porosity evolution may be associate with the biological oxidation mechanism.

The chemical and biological effects are major mechanisms for black shale oxidation $[1,3,4,11,13,17-$ $21]$, but the minerals-porosity correlations are mostly focus on the chemical mechanism $[4,5,11,18,22$, 23]. Our lab recently reported that Acidithiobacillus ferrooxidans (A. ferrooxidans) bacteria led to an increase of elemental $\mathrm{C}$ and a decrease of porosity on the shale micro-surface, which in contract to the oxidation behavior of acid solution [7]. However, that study mainly investigated the pyrite oxidation rate 
and micro-surface porosity characteristics at the initial oxidation stage (7 days), the overall alterations of other minerals and porosity evolution during black shale oxidation process was still unclear.

In present study, the acid solution and $A$. ferrooxidans bacteria were applied to simulate the chemical and biological effect during black shale oxidation process. The XRD analysis, organic carbon measurement, nitrogen absorption experiment and high-pressure mercury intrusion test, SEM observation and EDX line scanning analysis were carried out to measure the minerals composition, total organic carbon (TOC) content, porosity characteristics, micro-surface morphology and elemental concentrations of black shale samples. The targets of this study are, i) to analyse the different minerals composition and shale porosity characteristics under chemical and biological effects; ii) and to establish the correlation between minerals alteration and porosity evolution of black shale under biological oxidation mechanisms.

\section{Materials And Methods \\ 2.1. Sample preparation}

The black shale samples were collected from a mountainous area in Chengkou County, Chongqing City, China. The sample site, previously described by Li, et al [7], located at the elevation of $1000 \mathrm{~m}$ above sea level and the latitude and longitude of $31^{\circ} 57^{\prime} \mathrm{N}$ and $108^{\circ} 37^{\prime} \mathrm{E}$, respectively (Fig. 1 ). The fresh rock fragments were obtained at $10 \mathrm{~m}$ below the natural ground level, and cut into $0.3 \mathrm{~cm}$ (width) $\times 0.3 \mathrm{~cm}$ (length) $\times 0.3 \mathrm{~cm}$ (height) cubes. After cleaned by an ultrasonic cleaner with ethanol $(75 \%, \mathrm{v} / \mathrm{v})$ for $20 \mathrm{~min}$ and rinsed by deionized water for 5 times, samples were dried in a vacuum drying incubator at $40{ }^{\circ} \mathrm{C}$ and sterilized by UV irradiation for $12 \mathrm{~h}$. Approximately $30 \mathrm{~g}$ rock cubic was used for each group.

\subsection{Bacterial strain and culture media}

The $A$. ferrooxidans strain used in this study was isolated from the acidic groundwater near the sampling

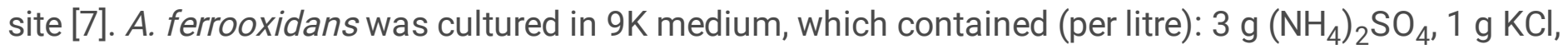
$0.5 \mathrm{~g} \mathrm{~K}_{2} \mathrm{HPO}_{4}, 0.5 \mathrm{~g} \mathrm{MgSO}_{4} \cdot 7 \mathrm{H}_{2} \mathrm{O}, 0.001 \mathrm{~g} \mathrm{Ca}\left(\mathrm{NO}_{3}\right)_{2}$, and $44.2 \mathrm{~g} \mathrm{FeSO}_{4} \cdot 7 \mathrm{H}_{2} \mathrm{O}$, with the pH adjusted to 2.50 with $\mathrm{H}_{2} \mathrm{SO}_{4}$. After $A$. ferrooxidans was cultivated to the logarithmic growth phase, the solid materials were removed using sterilized qualitative filter paper, and the cells were harvested by centrifugation $(2376 \times \mathrm{g})$. The resuspended cells were counted using a haemocytometer and the bacterial density was adjusted to $4 \times 10^{8}$ cells $/ \mathrm{mL}$ with a $\mathrm{H}_{2} \mathrm{SO}_{4}$ solution $(\mathrm{pH}=2.50)$.

\subsection{Experimental grouping}

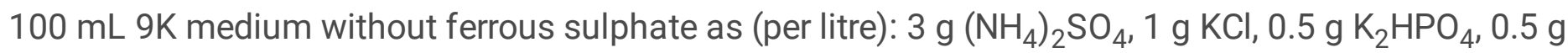
$\mathrm{MgSO}_{4} \cdot 7 \mathrm{H}_{2} \mathrm{O}$ and $0.001 \mathrm{~g} \mathrm{Ca}\left(\mathrm{NO}_{3}\right)_{2}$ was used for each group. The $\mathrm{pH}$ value in control group (G1) was approximately at 6.50 , and adjusted to $\mathrm{pH}=2.50$ with $\mathrm{H}_{2} \mathrm{SO}_{4}$ for the acid solution group (G2) and $A$. ferrooxidans group (G3). $10 \%$ of $A$. ferrooxidans cell suspension was inoculated to $\mathrm{G} 3$. All samples were immersed in a 250-mL Erlenmeyer flask and incubated in a constant temperature shaker at $28^{\circ} \mathrm{C}, 150 \mathrm{r} / \mathrm{p}$.

\subsection{Organic carbon measurement}


Total organic carbon (TOC) was measured using a C230 Elemental Analyzer (Leco Corporation, USA) as follows analysis procedure: approximately $100 \mathrm{mg}$ of dried and powdered black shale at 100-mesh was treated with $5 \% \mathrm{HCl}$ at $80{ }^{\circ} \mathrm{C}$ to remove any carbonate, and then washed six times with deionized water to remove residual $\mathrm{HCl}$. The treated powder was mixed with iron powder and a tungsten-tin alloy as additives, then combusted in the analyser at $3000^{\circ} \mathrm{C}$. The oxygen was added as the combustionaccelerating gas and nitrogen as the carrier gas. The TOC was calculated by integrating the area of the peak representing the $\mathrm{CO}_{2}$ generated from the combustion of organic matter.

\subsection{XRD analysis}

The XRD diffraction analysis (Bruker, Karisruhe, Germany) was performed for the minerals composition analysis. The X-rays used Cu Ka radiation $(\lambda=1.54060)$ at a voltage of $40 \mathrm{kV}$ and a current of $40 \mathrm{~mA}$, with a scanning range $2.5852^{\circ}(2 \theta)$ and a scanning step length of $0.01^{\circ}(2 \theta)$, a Cu filament and Ni filter was performed for the qualitative mineral analysis.

\subsection{Nitrogen adsorption and high-pressure mercury intrusion tests}

Nitrogen adsorption tests by a Quadrasorb SI Surface Area and Porosity Analyzer (Quantachrome, American) were performed to measure the samples specific surface area and the pore size distribution with range of $0.35 \mathrm{~nm} \sim 400 \mathrm{~nm}$. The test procedures were as follows: approximately $0.5 \mathrm{~g}$ of powdered shale was initially degassed at $150^{\circ} \mathrm{C}$ for 3 hours to remove moisture and residual volatiles. Then the pure nitrogen at $-197.3^{\circ} \mathrm{C}$ with a purity greater than $99.999 \%$ was used for relative absorption properties measurement. For specific surface area (surface area per unit gram) measurement, a modified BET technique was applied to invert the adsorption isotherm and calculate the specific surface area, as suggested by Rouquerol et al. $[15,24]$. The pore volume was obtained from the Gurevich rule $[25,26]$ and the pore size distribution was obtained by applying the Barrett, Johner and Halenda (BJH) method [27] from the adsorption isotherm, in the pore size range of $1.7 \mathrm{~nm} \sim 150 \mathrm{~nm}$ and relative pressures $\left(P / P_{0}\right)$ of $0.06 \sim 0.99$.

The high-pressure mercury intrusion (HPMI) test was performed to obtain pore size distributions of macropores larger than $100 \mathrm{~nm}{ }^{[28,29]}$, crushed and dried samples were injected mercury at given pressure, a Micromeritics AutoPore IV 9500 Porosimeter (USA) was used to record the injected volume and calculated the pores diameter using the Laplace-Washburn equation [28].

According to the IUPAC (International Union of Pure and Applied Chemistry) pore classification method [25], pores were classified into micropores ( $<2 \mathrm{~nm}$ pore width), mesopores ( $2 \sim 50 \mathrm{~nm}$ pore width), and macropores (> $50 \mathrm{~nm}$ pore width).

\subsection{SEM analyses and EDX line scanning}

The scanning electron microscopy (SEM) with energy dispersive X-ray spectroscopy (EDX) was used for rock surface microstructure analysis and specific elements identification (Zeiss, Heidenheim, Germany). 
The working condition of SEM was at acceleration voltage of $20 \mathrm{kV}$, extraction voltage of $4.9 \mathrm{kV}$ and emission current of $10 \mu \mathrm{A}$. The EDX line scanning was operated at an excitation voltage of $20 \mathrm{kV}$, and an energy range of $0 \sim 20 \mathrm{keV}$, the acquisition time was $100 \mathrm{~s}$ (point analysis) and 1800s (line scan), with processing and dead time of $35 \% \sim 40 \%$.

\section{Results}

\subsection{Geochemical composition}

Table 1 shows the content of total organic carbon (TOC), pyrite and clay minerals before and after treatment. The minerals content is significantly altered after treatment, the most change presents in the chemical group (G2). As shown in Table 1, the decreased ratio of pyrite content in G2 is near triple and double greater than that in control group (G1) and biological group (G3), respectively. Whereas the increased ratio of total clay minerals (TCM) is about 8-folds and 1.5-folds greater than that in G1 and G3, respectively, the increased TCM is mainly Smectite. The alter trends of TOC content are different in G2 and G3, which decrease by $44.2 \%$ in G2 but increase by $48.3 \%$ in G3, respectively. Notably, at the initial oxidation stage, the minerals reaction rates are similar in $\mathrm{G} 2$ and $\mathrm{G} 3$, the pyrite decreased by $21.6 \%$ and $20.8 \%$, and the TCM increased by $7.9 \%$ and $11.9 \%$ in G2 and G3 at the 7th day, respectively, but these reactions seem to subsequently slow down in G3, result in a less change of pyrite and TCM content than that in $\mathrm{G} 2$ at the 30th day. 
Table 1

The total organic carbon, pyrite and clay minerals content (in weight \%) of black shale samples before and after treatment

\begin{tabular}{|lllllll|}
\hline $\begin{array}{l}\text { Time } \\
(\mathbf{d})\end{array}$ & Group & $\begin{array}{l}\text { TOC } \\
\text { (\%) }\end{array}$ & $\begin{array}{l}\text { Pyrite } \\
\text { (\%) }\end{array}$ & $\begin{array}{l}\text { TCM } \\
\text { (\%) }\end{array}$ & $\begin{array}{l}\text { Illite } \\
(\%)\end{array}$ & $\begin{array}{l}\text { Smectite } \\
(\%)\end{array}$ \\
\hline 0 & G1 & 2.37 & 1.81 & 37.5 & 28.3 & 9.2 \\
\hline & G2 & 2.06 & 1.94 & 40.5 & 29.2 & 11.3 \\
\hline 7 & G3 & 1.78 & 2.02 & 37.0 & 24.9 & 12.1 \\
\hline & G1 & 2.30 & 1.71 & 37.7 & 28.5 & 9.2 \\
\hline 15 & G3 & 2.11 & 1.60 & 41.4 & 26.5 & 14.9 \\
\hline & G2 & 1.72 & 1.11 & 45.7 & 31.1 & 14.6 \\
\hline & G3 & 2.43 & 1.51 & 42.5 & 26.8 & 15.7 \\
\hline 30 & G1 & 2.26 & 1.50 & 38.7 & 28.9 & 9.8 \\
\hline & G2 & 1.15 & 0.98 & 50.5 & 33.7 & 16.8 \\
\hline & G3 & 2.64 & 1.46 & 43.8 & 27.2 & 16.6 \\
\hline
\end{tabular}

\subsection{Adsorption isotherms}

Figure 2 shows the adsorption isotherms of nitrogen at liquid temperature $\left(-197.3^{\circ} \mathrm{C}\right)$ of each sample.

The porosity characteristics can be qualitative assessed by the shape of isotherms $[15,16]$, which similar in original samples (Fig. 2a). At the initial stage, the adsorption isotherms raise rapidly, indicating a certain amount of micropores existed. With the increase of relative pressure, the adsorption isotherm shows a significant hysteresis pattern closed to the Type IV isotherm [26], and follows by a steep slopes at the relative pressure range of $0.98 \sim 1.00$, indicating the samples contained both mesopores and macropores.

After treated by different solution at predetermined period, the isotherms shape exhibits differential trends at predetermined periods (Fig. $2 \mathrm{~b}-2 \mathrm{~d}$ ). In G1, the absorbed volume is stable at low pressure $(<0.1)$, but gradually increases at the intermediate- and high- relative pressure. At the 30th day, the absorbed volume increases by $44.8 \%$ and $69.1 \%$ at the relative pressure of 0.5 and 1.0, respectively (Fig. $2 \mathrm{~d}$ ), indicating the mesopores and maropores all increased. In G2, the absorbed volume remarked increases throughout the range of relative pressure, and increases by $97.2 \%, 98.9 \%$ and $95.1 \%$ at relative pressure of $0.1,0.5$ and 1.0 at the 30th day, respectively (Fig. 2d), indicating a more increase in all scales of pores occurred in G2. In $\mathrm{G} 3$, the absorbed volume increases initially, by $77.3 \%, 81.4 \%$ and $68.5 \%$ at relative pressure of $0.1,0.5$ and 1.0 at the 15th day, these increments even greater than that in $\mathrm{G} 2$ at the same time (Fig. 2c). 
However, the absorbed volume seems "stead" subsequently, and it finally increases by $74.7 \%, 73.9 \%$ and $81.3 \%$ at relative pressure of $0.1,0.5$ and 1.0 at the 30 th day (Fig. $2 \mathrm{~d}$ ).

\subsection{Pore size distribution}

Figure 3 shows the pore size distribution characteristics results combined the nitrogen absorption isotherms and high pressure mercury injection analysis. The bimodal distribution characteristics of original samples are similar, including a major peak around $30 \mathrm{~nm}$ and a minor peak at $60 \mathrm{~nm} \sim 100 \mathrm{~nm}$ (Fig. 3a). Experimental treatments have not changed the bimodal patterns but increased the porosity (Fig. 3b-d). The most increment of pore volume range is observed in $\mathrm{G} 2$, is by $72.7 \%$ and $82.9 \%$ at major and minor peak (Fig. 3d), close to the total pore volume increment (89.1\%) (Table. 2). In biological group (G3), the pore volume range increases by $36.9 \%$ at major peak but decreases by $45.7 \%$ at the minor peak (Fig. 3d), which may explain a $21.5 \%$ increment of total pore volume in G3 (Table. 2). A moderate change occurs in $\mathrm{G} 1$, the pore volume range increases by $12.5 \%$ and $20.6 \%$ at the major and minor peak, respectively (Fig. 3d), corresponds a $29.5 \%$ increase of total pore volume (Table. 2).

\subsection{Specific surface area and pore volume}

Table 2 shows the calculated specific surface areas, pore volume and average pore diameter before and after treatment. The chemical effect has the most increment both in the specific surface areas and pore volume. Compared with original samples, these parameters increase by $5.4 \%, 29.5 \%$, and $1 \%$ in $\mathrm{G} 1$, by $61 \%, 89.1 \%$, and $2.8 \%$ in G2, and by $31.4 \%, 21.5 \%$, and $1.5 \%$ in G3 (Table 2), respectively. The micro-, meso- and macro- pores differently influence the specific surface areas and pore volume. As shown in Fig. 4, the mesopores predominately (more than 70\%) determine the specific surface areas and pore volume, and have not significantly changed after treatment (less than 1\%). The ratio of micropores in specific surface areas was higher than macropores (21.35\% 27.51\% vs. 1.5\% 4.35\%) (Fig. 4a), but is lower $(4.38 \% \sim 7.69 \%$ vs. $16.24 \% \sim 19.93 \%)$ in pore volume (Fig. 4b). The micropores decrease and the macropores increase in $\mathrm{G} 2$, so the increase of pore volume is more than the increase of specific surface areas (89.1\% vs. 61\%). Whereas the micropores increase and the macropores decrease in G3, so the increase of pore volume is less than the increase of specific surface areas (21.5\% vs. 31.4\%) (Table 2). 
Table 2

Pore structure parameters of black shale samples from nitrogen absorption isotherms

\begin{tabular}{|c|c|c|c|c|}
\hline $\begin{array}{l}\text { Time } \\
\text { (d) }\end{array}$ & Group & $\begin{array}{l}\text { Specific surface area } \\
\left(\mathrm{m}^{2} / \mathrm{g}\right)\end{array}$ & $\begin{array}{l}\text { Pore volume } \\
\left(\mathrm{cm}^{3} / \mathrm{g}\right)\end{array}$ & $\begin{array}{l}\text { Average pore diameter } \\
(\mathrm{nm})\end{array}$ \\
\hline \multirow[t]{3}{*}{0} & $\mathrm{G} 1$ & 20.79 & 0.061 & 33.55 \\
\hline & $\mathrm{G} 2$ & 21.05 & 0.064 & 33.45 \\
\hline & G3 & 21.98 & 0.065 & 33.61 \\
\hline \multirow[t]{3}{*}{7} & $\mathrm{G} 1$ & 21.34 & 0.066 & 33.68 \\
\hline & $\mathrm{G} 2$ & 27.78 & 0.076 & 33.93 \\
\hline & G3 & 27.11 & 0.073 & 33.91 \\
\hline \multirow[t]{3}{*}{15} & $\mathrm{G} 1$ & 21.79 & 0.073 & 33.73 \\
\hline & $\mathrm{G} 2$ & 30.01 & 0.089 & 34.10 \\
\hline & G3 & 28.47 & 0.076 & 33.97 \\
\hline \multirow[t]{3}{*}{30} & G1 & 21.92 & 0.079 & 33.86 \\
\hline & $\mathrm{G} 2$ & 33.86 & 0.121 & 34.38 \\
\hline & G3 & 28.89 & 0.079 & 34.10 \\
\hline
\end{tabular}

\subsection{SEM image}

The microstructure of original samples is dominated by clay minerals, a multiple scale of pores, such as triangular pores, slit pores and cracks are observed on shale micro-surface (Fig. 5a) and significantly increase after treatment. In G1, the continuous clay matrix is destroyed and formed a lot of intragranularses dissolved holes, with wedge-shaped, oval, or irregular structures (Fig. 5b). The chemical effect lead to a similar but more remarked damage than G1, a large amount of channels and dissolved pores is observed on shale surface, with elliptical, cylindrical or irregularly shape (Fig. 5c), as reported by Ling, et al on weathered black shale profiles [5]. In G3, a lot of loosen, round cake-shaped and short rodlike materials are cover on the rock surface and form many irregular polygonal pores (Fig. 5d).

\subsection{EDX line scans analysis}

Figure 6 shows the relative elemental concentrations of black shale samples from surface to interior subsurface (Fig. 6e). Elemental $\mathrm{Si}, \mathrm{O}, \mathrm{C}, \mathrm{Al}, \mathrm{S}, \mathrm{Fe}, \mathrm{Ca}, \mathrm{K}$, and $\mathrm{Mg}$ are heterogeneous distributed at each point (Fig. 6a), experimental treatments significantly change the relative proportion with respect to a $2 \mu \mathrm{m}$ depth (Fig. 6b-d). The elemental Si and $\mathrm{O}$ are among the most stable elements which kept a high proportion throughout the experiment. Whereas the relative proportion of elemental $\mathrm{Al}, \mathrm{S}, \mathrm{Fe}, \mathrm{Ca}, \mathrm{K}$, and Mg decrease by more than 90\% in G2 (Fig. 6c), and by approximately 50\% in G1 (Fig. 6b) and in 
G3(Fig. 6d), respectively. In consistent to the minerals alterations, the relative proportion of elemental C decreased in $\mathrm{G} 1$ and $\mathrm{G} 2$, but increased in $\mathrm{G} 3$.

\section{Discussion}

The correlation between minerals composition and porosity evolution is an essential topic for black oxidation process. A series of minerals reactions change the shale porosity, in turn, the evolution of porosity, especially the "active" pores -enable oxygen and fluids flow into - determine the fluid-rock reactions areas and control the kinetic rate of minerals reactions [3, 4, 12, 30-36]. Previous studies have well established the minerals-porosity correlations based on the chemical oxidation mechanism, but as a basic oxidation mechanism, the role of biological effect is seldom to report.

In present study, two classic effects -acid solution and $A$. ferrooxidans-were applied to simulate the chemical and biological oxidized black shale process, respectively. The results suggest that the chemical and biological effects led to varied alterations of minerals composition and porosity evolution, mainly due to the different alter trends of TOC content.

The acid solution was proven to accelerate the organic matters oxidation $[9,10,13]$, that can penetrate the decrease of TOC content in G2. But the A. ferrooxidans, to our acknowledgements, majorly promoted the pyrite oxidation [37-41], so it hard to directly explain the increase of TOC content in G3. Previous studies proposed that the $A$. ferrooxidans cell bodies will attach on the rock surface when oxidize the pyrite [37, 39], so the coverage of rod-like material on the shale surface (Fig. 5d) and the accumulation of elemental C (Fig. 6d) on the shale microsurface may be the attached $A$. ferrooxidans cell bodies. Liu et al. [42] also reported an accumulation of organic matters on the rock surface during $A$. ferrooxidans oxidized ore contained pyrite; Jin et al. proposed the addition of modern organic matters at the regolith surface was associated with the biological turbulence such as the plant leaves, animal feces and microbial carcasses [4]. Therefore, the increase of TOC in G3 can be contribute to the attachment and dead $A$. ferrooxidans cell bodies.

Due to the ability of blocking rock pores and inhibiting fluid-rock interactions, the organic matter is generally recognized as a negative factor for porosity evolution $[4,10,15,43]$. But researchers also reported a positive relation between the specific surface area and organic matters content $[11,16]$, probably since the different contributions of micropores and macropores to the specific surface areas and pore volume. Kuila et al and Fisher et al reported a double value of specific surface areas obtained by nitrogen absorption experiment than by high-pressure mercury intrusion test which can not measure the micropores $[11,15]$.

We found that the chemical effect mainly increases the amount of macropores, whereas the biological effect mainly increases the amount of micropores. As shown in Fig. 4, the ratio of micropores in the specific surface areas (more than $20 \%$ ) is much more than in the pore volume (less than $5 \%$ ), that can explain a more reduction of pore volume than the specific surface areas occurred in G3. However, these micropores may be "inactive" -where oxygen and fluid can not flow into, resulting in the lower fluid-rock 
reaction areas and rates. Therefore, we found that the most reduction of TOC in G2 accompanied by the most decrease of pyrite and increase of clay minerals content among groups. Whereas the increase of TOC in G3 resulted in less change in pyrite and clay minerals content than that in G2.

Pearson correlation coefficients for relationships between pores volume and minerals content indicated that the TOC content is positively correlated with micorpores and mesopores in biological group $(R=0.72$, $0.97)$, whereas it negatively correlates with mesopores and macropores in chemical group $(R=-0.93$, -0.94) (Fig. 7).

In summary, we propose that the increase of TOC in biological group impacts the correlation between minerals alteration and porosity evolution during black shale oxidation. The probably pathway is as follows: Initially, A. ferrooxidans promotes the pyrite oxidation and porosity formation, so the minerals content and porosity characteristics are similar between chemical and biological groups. With the processing of oxidation, the attached and dead $A$. ferrooxidans bodies blocked the large pores and decrease the rock-fluid reaction areas, then slow down the minerals reaction rate in biological group.

\section{Conclusion}

A laboratory study on black shale from the Chengkou County in the Southwest Mountains of China was carried out, revealed the different correlations between minerals alteration and porosity evolution under chemical and biological effects. The summarized results indicate that,

(1) The decrease of pyrite content and increase of clay minerals was more in chemical group than that in biological group, may be attributed to the chemical effect decrease but the biological effect increased the TOC.

(2) The increase of TOC increases the amount of macropores in chemical group but the decrease of TOC increase the amount of micropores in biological group, resulting in the more specific surface areas and pore volume in chemical group.

(3) The attached and dead A. ferrooxidans may contribute to the increase of TOC and surface elemental $\mathrm{C}$ in biological group, which is not favour to the pore volume and led to a less fluid-rock reaction areas, resulting in a lower minerals reaction rate in biological group than that in chemical group.

It suggested that the difference of chemical and biological effect in the correlation of minerals alteration and porosity evolution during black shale oxidation process may be attributed to the organic matters content alteration.

\section{Declarations}

\section{Acknowledgements}


We would like to thank the anonymous reviewers for their constructive comments that enabled us to improve the manuscript.

\section{Authors' contributions}

Jing Li and Qi Li carried out the experiments and analysis. Baolong Zhu had the idea for the project.All authors read and approved the manuscript.

\section{Funding}

This research was financiallysupported by National Natural Science Foundation of China (Grant NO.:41672342,41472256).

\section{Availability of data and materials}

All results and data of this article are available in the paper.

\section{Consent for publication}

All authors have consented to publication.

\section{Competing interests}

The authors declare that they have no competing interests.

\section{Author details}

School of Civil Engineering and Architecture,Southwest University of Science and Technology, Mianyang 621010, China

\section{References}

1. Kolowith LC, Berner RA (2002) Weathering of phosphorus in black shales. Global Biogeochem Cycles 16: $87-81-87-8$

2. Formoso MLL (2006) Some topics on geochemistry of weathering: a review. An Acad Bras Cienc 78:809-820

3. Brantley SL, White AF (2009) Approaches to Modeling Weathered Regolith [J]. Rev Mineral Geochem 70:435-484

4. Jin L, Mathur R, Rother G, Cole D, Bazilevskaya E, Williams J, Carone A, Brantley S (2013) Evolution of porosity and geochemistry in Marcellus Formation black shale during weathering. Chem Geol 356:50-63

5. Ling S, Wu X, Zhao S, Liao X (2018) Evolution of porosity and clay mineralogy associated with chemical weathering of black shale: A case study of Lower Cambrian black shale in Chongqing, 
China. J Geochem Explor 188:326-339

6. Xu J, Peng B, Yu C, Yang G, Tang X, Tan C, Xie S, Tu X, Bao Z, Quan M, Xiao M (2012) Geochemistry of soils derived from black shales in the Ganziping mine area, western Hunan, China. Environ Earth Sci 70:175-190

7. Li Q, Zhu B, Li J (2020) A comparative study on the micro- surface characteristics at black shale initial oxidation stage. Sci Rep. DOI:10.1038/s41598-020-67268-z

8. Zhu B, Li Q, Wu Y, Li J (2020) Analytical Model for Predicting Stress Distribution and Load Transfer of Tension-Type Anchor Cable with Borehole Deviation. Int J Geomech 20:1-13

9. Tang X, Zhang J, Liu Y, Yang C, Chen Q, Dang W, Zhao P (2018) Geochemistry of organic matter and elements of black shale during weathering in Northern Guizhou, Southwestern China: Their mobilization and inter-connection. Chem Erde 78:140-151

10. Marynowski L, Kurkiewicz S, Rakociński M, Simoneit BRT (2011) Effects of weathering on organic matter: I. Changes in molecular composition of extractable organic compounds caused by paleoweathering of a Lower Carboniferous (Tournaisian) marine black shale. Chem Geol 285:144156

11. Fischer C, Gaupp R (2005) Change of black shale organic material surface area during oxidative weathering: Implications for rock-water surface evolution. Geochim Cosmochim Acta 69:1213-1224

12. Røyne A, Jamtveit B, Mathiesen J, Malthe-Sørenssen A (2008) Controls on rock weathering rates by reaction-induced hierarchical fracturing. Earth Planetary Science Letters 275:364-369

13. Berner RA, Bolton EW, Wildman RA, Petsch ST (2015) Organic matter weathering and atmospheric oxygen: a field and modeling study of black shale oxidation. Proceedings of the 11th International Symposium on Water-Rock Interaction

14. Yang C, Zhang J, Tang X, Ding J, Zhao Q, Dang W, Chen H, Su Y, Li B, Lu D (2017) Comparative study on micro-pore structure of marine, terrestrial, and transitional shales in key areas, China. Int $\mathrm{J}$ Coal Geol 17:176-192

15. Kuila U, Prasad M (2013) Specific surface area and pore-size distribution in clays and shales. Geophys Prospect 61:341-362

16. Yang F, Ning ZF, Zhang SD (2013) Characterization of shale pore structure based on nitrogen adsorption experiment. Gas industry 33:135-140

17. Fischer C, Karius V, Thiel V (2007) Organic Matter in Black Slate Shows Oxidative Degradation Within Only a Few Decades. J Sediment Res 77:355-365

18. Kennedy MJ (2002) Mineral Surface Control of Organic Carbon in Black Shale. Science 295:657-660

19. Li X, Zhu B, Wu X (2016) Swelling characteristics of soils derived from black shales heightened by cations in northern Chongqing, China [J]. J Mt Sci 13:1107-1119

20. Liu W, Zhang XL (2011) Evidence for microbial dissolution of pyrite from the Lower Cambrian oolitic limestone, South China. Biogeosciences Discussions 8:2035-2056 
21. Matlakowska R, Sklodowska A (2011) Biodegradation of Kupferschiefer black shale organic matter (Fore-Sudetic Monocline, Poland) by indigenous microorganisms. Chemosphere 83:1255-1261

22. Löhr SC, Baruch ET, Hall PA, Kennedy MJ (2015) Is organic pore development in gas shales influenced by the primary porosity and structure of thermally immature organic matter? Org Geochem 87:119-132

23. Petsch ST (2000) A field study of the chemical weathering of ancient sedimentary organic matter. Org Geochem 31:475-487

24. Rouquerol J, Llewellyn P, Rouquerol $F(2007)$ Is the BET equation applicable to microporous adsorbents? Stud Surf Sci Catal 160:49-56

25. Gregg SJ, Sing KSW (1983) Adsorption, Surface Area, and Porosity, 2nd edn. Academic Press, New York

26. Rouquerol J, Rouquerol F, Sing KSW (1998) Absorption by Powders and Porous Solids. Academic Press

27. Barrett EP, Johner LS, Halenda PP (1951) The determination of pore volume and area distribution in porous substances. I. Computations from nitrogen isotherms. J Am Chem Soc 73:373-380

28. Washburn EW (1921) Note on a method of determining the distribution of pore sizes in a porous material. Proceedings of the National Academy of Sciences 7: 115-126

29. Cai Y, Liu D, Pan Z, Yao Y, Li J, Qiu Y (2013) Pore structure and its impact on CH4 adsorption capacity and flow capability of bituminous and subbituminous coals from Northeast China. Fuel 103:258268

30. Wu XY, Liao X, Zhao SY, Ling SX, Zhu BL (2014) Experimental study of the water-rock chemical reaction in black shale. Acta Geoscientica Sinica 35:573-581

31. Bérubé M-A, Locat J, Gélinas P, Chagnon J-Y, Lefrançois $P$ (1986) Black shale heaving at Sainte-Foy, Quebec, Canada. Can J Earth Sci 23:1774-1781

32. Parviainen A, Loukola-Ruskeeniemi K (2019) Environmental impact of mineralised black shales. Earth Sci Rev 192:65-90

33. Peuckerehrenbrink B, Hannigan RE (2000) Effects of black shale weathering on the mobility of rhenium and platinum group elements. Geology 28:475-478

34. Phan TT, Paukert Vankeuren AN, Hakala JA (2018) Role of water - rock interaction in the geochemical evolution of Marcellus Shale produced waters. Int J Coal Geol 191:95-111

35. Pilewski J, Sharma S, Agrawal V, Hakala JA, Stuckman MY (2019) Effect of maturity and mineralogy on fluid-rock reactions in the Marcellus Shale. Environ Sci Process Impacts 21:845-855

36. Renock D, Landis JD, Sharma M (2016) Reductive weathering of black shale and release of barium during hydraulic fracturing. Appl Geochem 65:73-86

37. Valdés J, Pedroso I, Quatrini R, Dodson RJ, Tettelin H, Blake R, Eisen JA, Holmes DS (2008) Acidithiobacillus ferrooxidans metabolism: from genome sequence to industrial applications. BMC Genom 9:597 
38. Nemati M, Webb C (1997) A kinetic model for biological oxidation of ferrous iron by Thiobacillus ferrooxidans. Biotechnology Bioengineering 53:478-486

39. Liu H, Lu X, Zhang L, Xiang W, Zhu X, Li J, Wang X, Lu J, Wang R (2018) Collaborative effects of Acidithiobacillus ferrooxidans and ferrous ions on the oxidation of chalcopyrite. Chem Geol 493:109-120

40. Fowler TA, Holmes PR, Crundwell FK (1999) Mechanism of Pyrite Dissolution in the Presence ofThiobacillus ferrooxidans [J]. Applied Environmental Microbiology 65:2987-2995

41. Jiang L, Zhou H, Peng X (2007) Bio-oxidation of pyrite, chalcopyrite and pyrrhotite by Acidithiobacillus ferrooxidans. Chin Sci Bull 52:2702-2714

42. Liu JY, Tao XX, He H, Zhao YD, Sun WC (2013) Biooxidation of Elemental Sulfur by Acidophilus Thiobacillus Ferrooxidans. Journal of Fuzhou University 41:1137-1141

43. Ling S, Wu X, Zhao S, Liao X, Ren Y, Zhu B (2014) Geochemical mass balance and elemental transport during the weathering of the black shale of Shuijingtuo formation in Northeast Chongqing, China. Scientific World Journal 742950

\section{Figures}

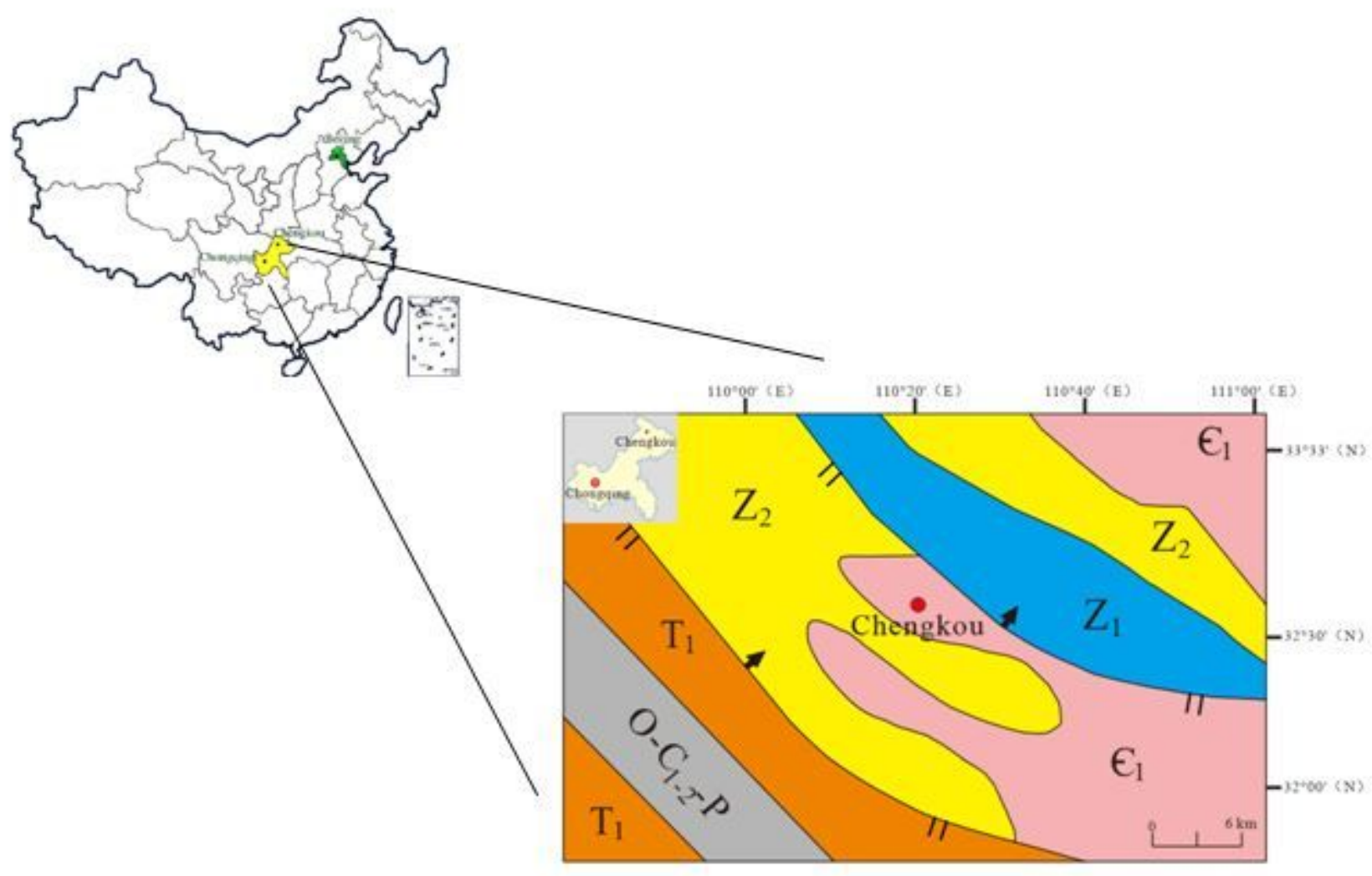

\section{Figure 1}

Sampling site in Chengkou County, Chongqing City, China 

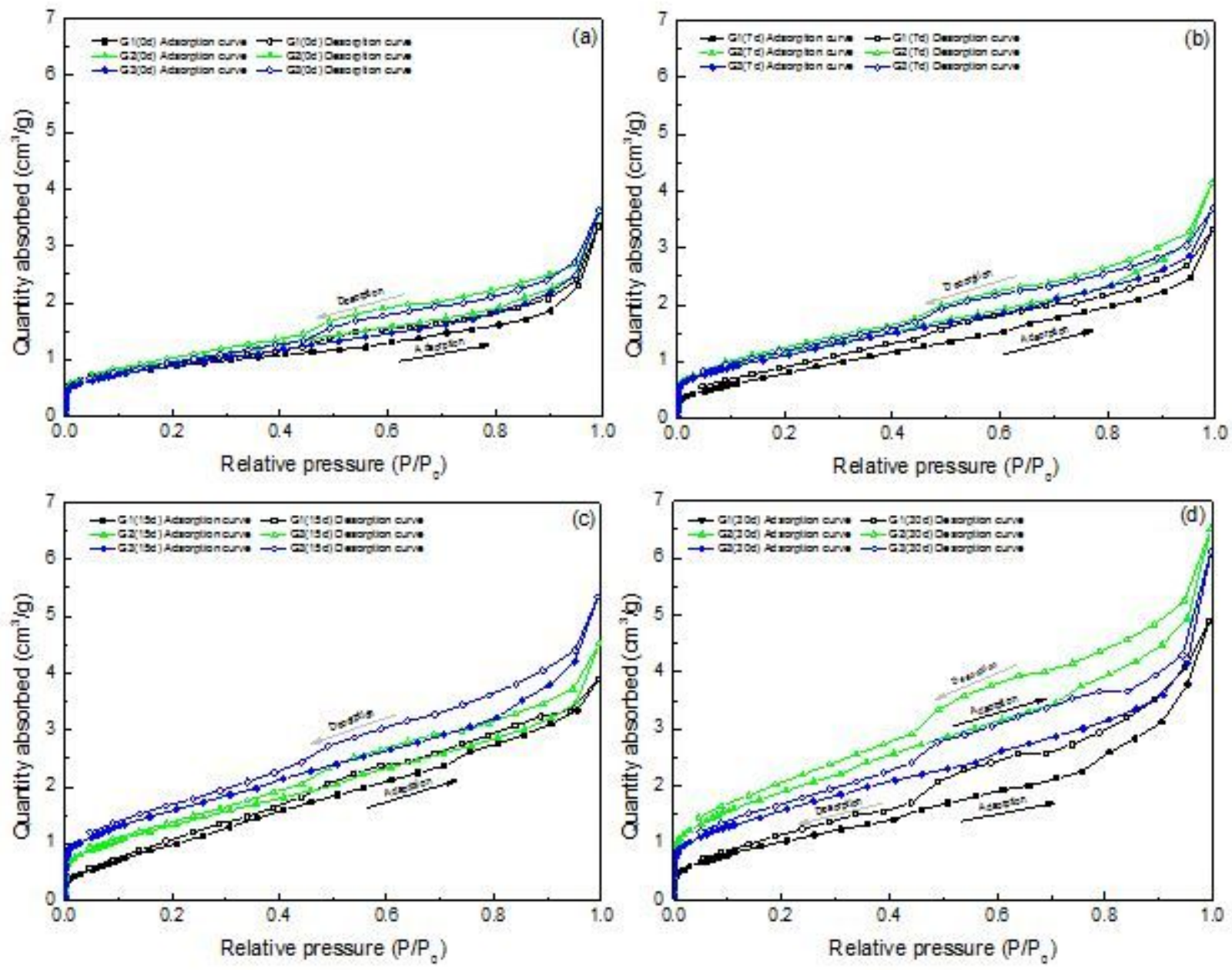

Figure 2

Nitrogen adsorption-desorption isotherms of black shale samples in different groups at 0 day (a), 7thday (b), 15thday (c) and 30th day (d). 

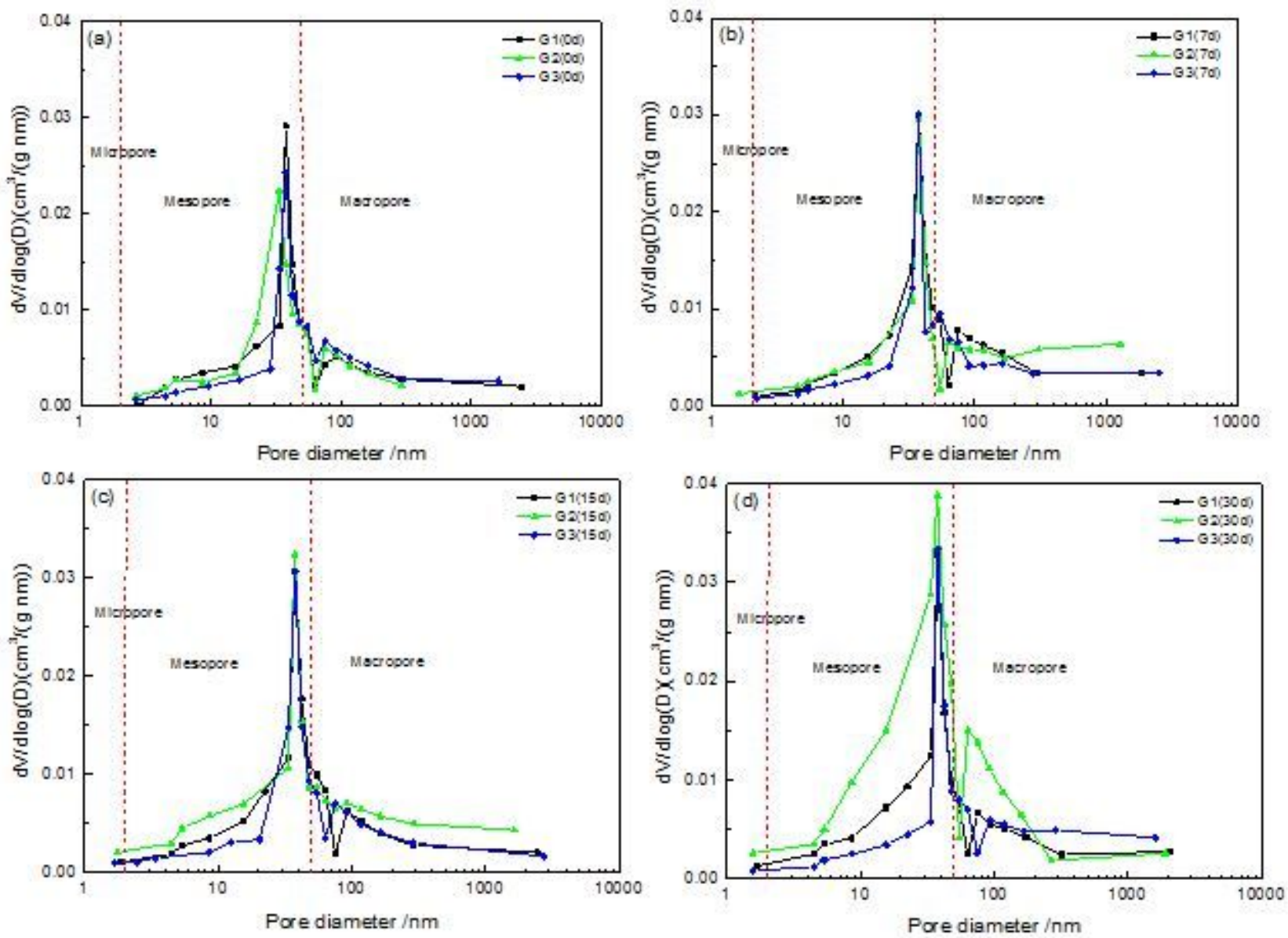

\section{Figure 3}

Pore size distribution characteristics obtained from the nitrogen absorption isotherm of samples in different groups at 0 day (a), 7thday (b), 15thday (c) and 30th day (d). 

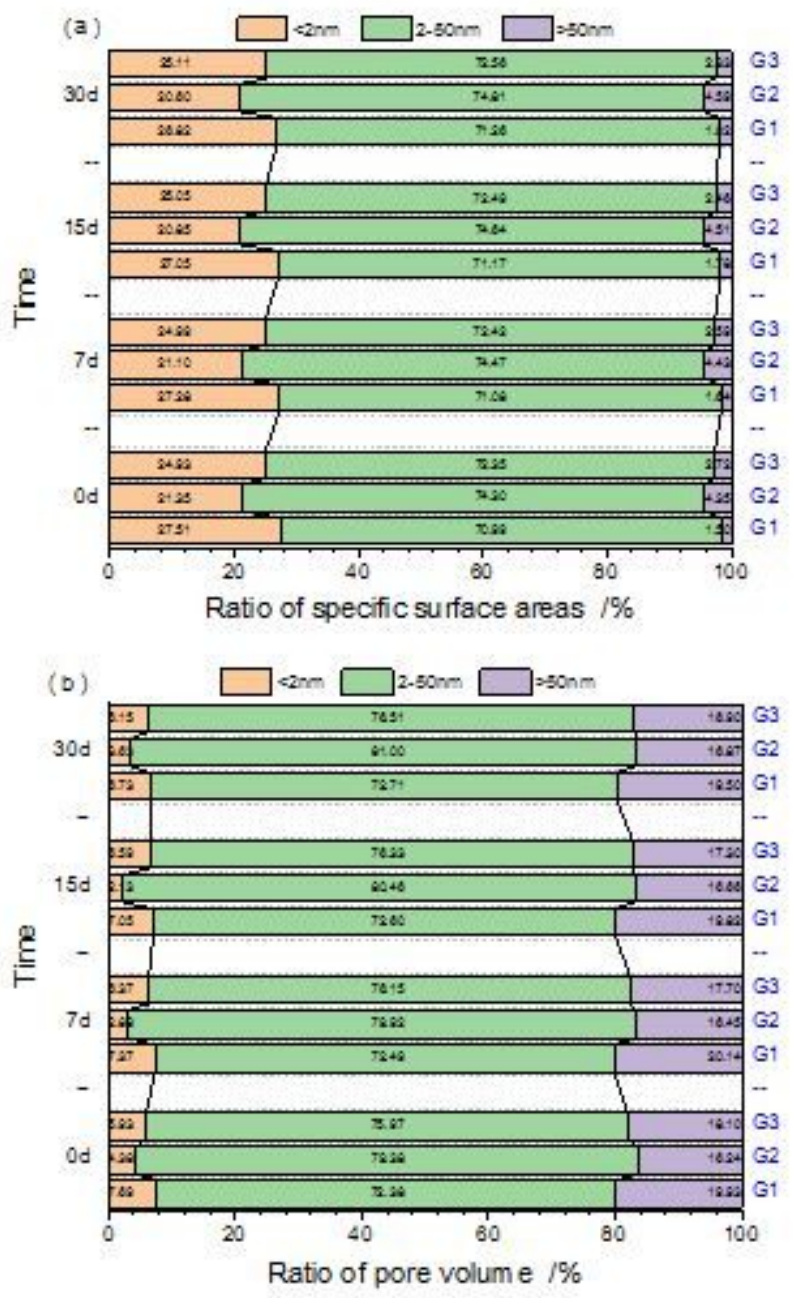

Figure 4

The relative retio of micro-, meso- and macro-pores in the specific surface areas (a) and pore volume (b) of black shale samples. 

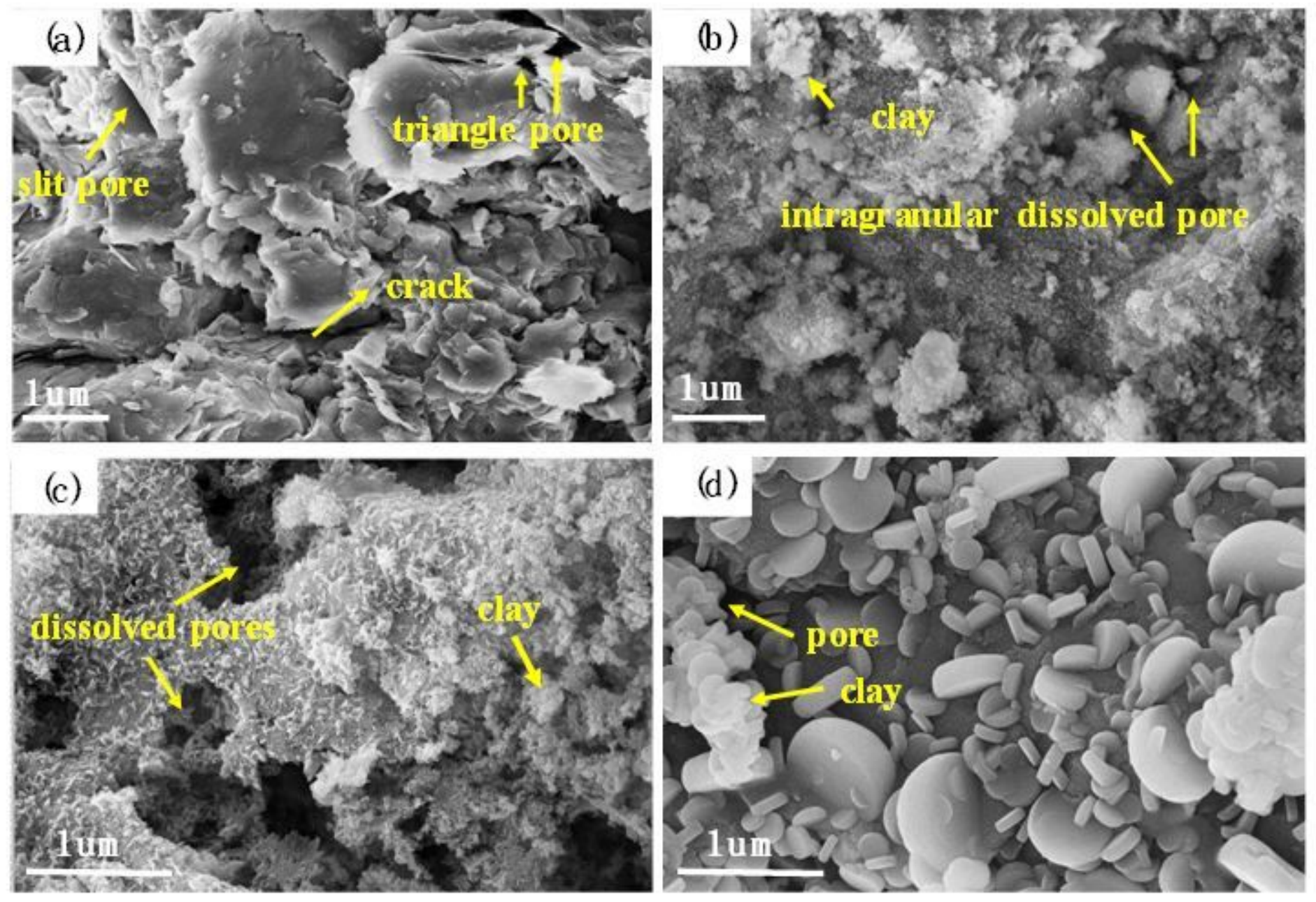

\section{Figure 5}

SEM image of black shale samples before (a) and treated for 30 days in G1 (b), G2 (c) and G3 (d). 

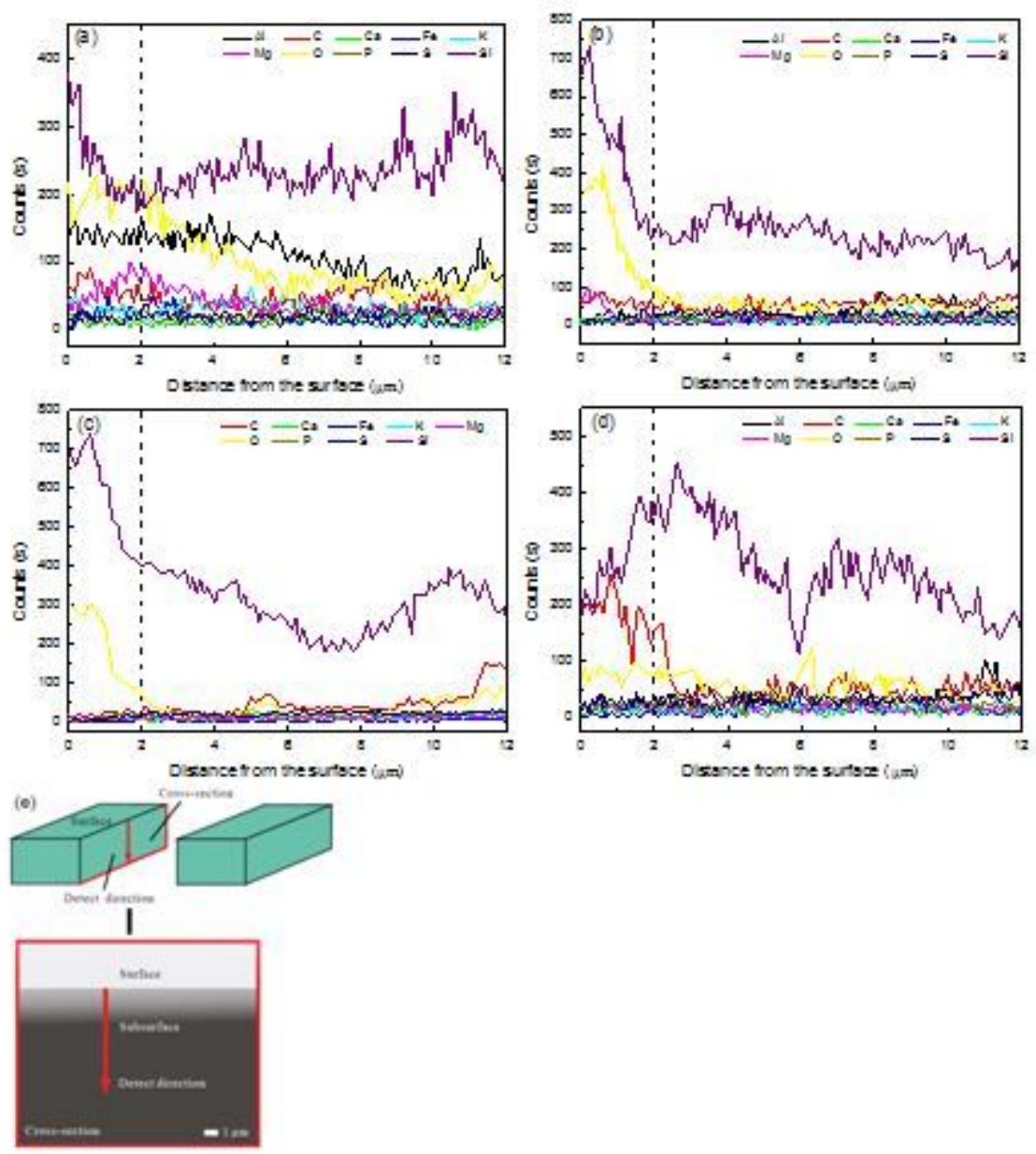

\section{Figure 6}

EDX line scans analysis of shale surface elements before (a) and treated for 30 days in G1 (b), G2 (c) and G3 (d),the dashed lines indicate the relative proportion of each element with a depth of $2 \mu \mathrm{m}$ range. The schematic diagram (e) indicates the scan direction of the sample. 

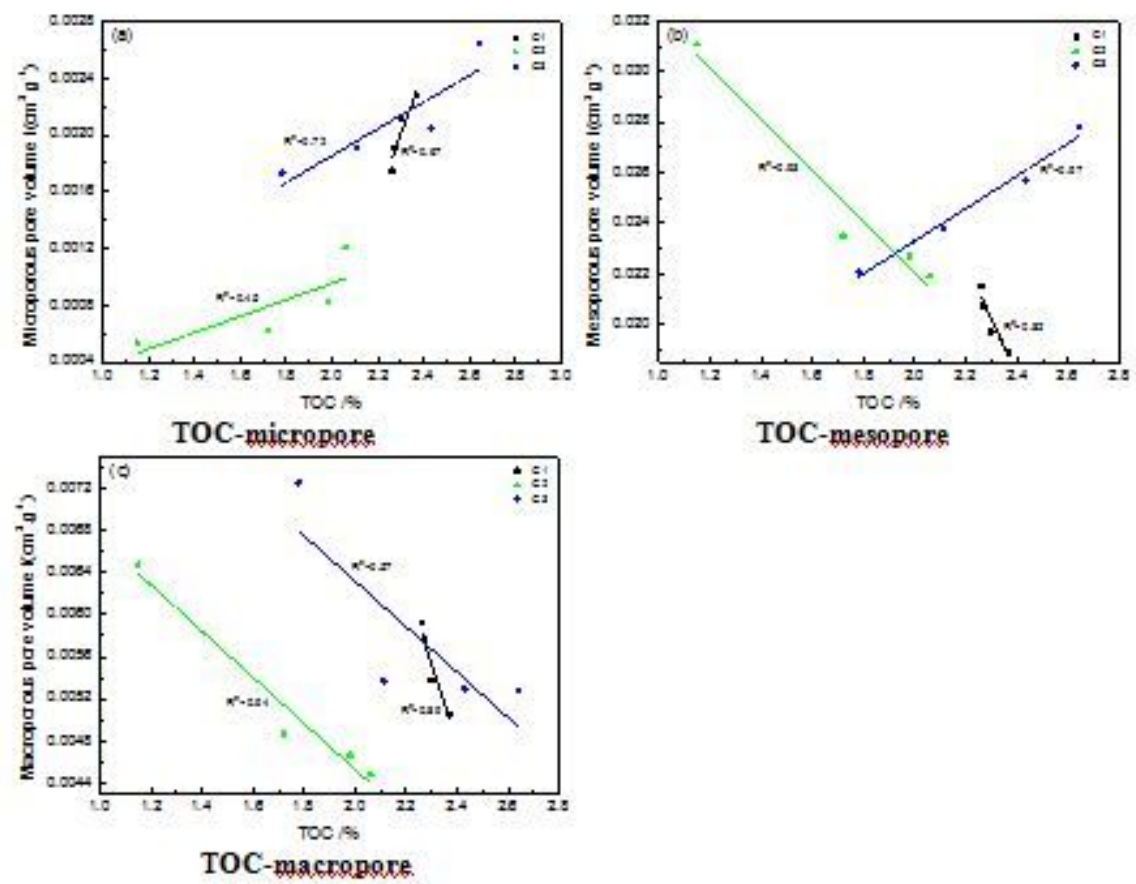

TOC-mesppore

\section{Figure 7}

Correlation between theTOC content and the amount of shale micro-pores (a), meso-pores (b) and macropores (c)in different group.

\section{Supplementary Files}

This is a list of supplementary files associated with this preprint. Click to download.

- SupplementarymaterialV5.docx 